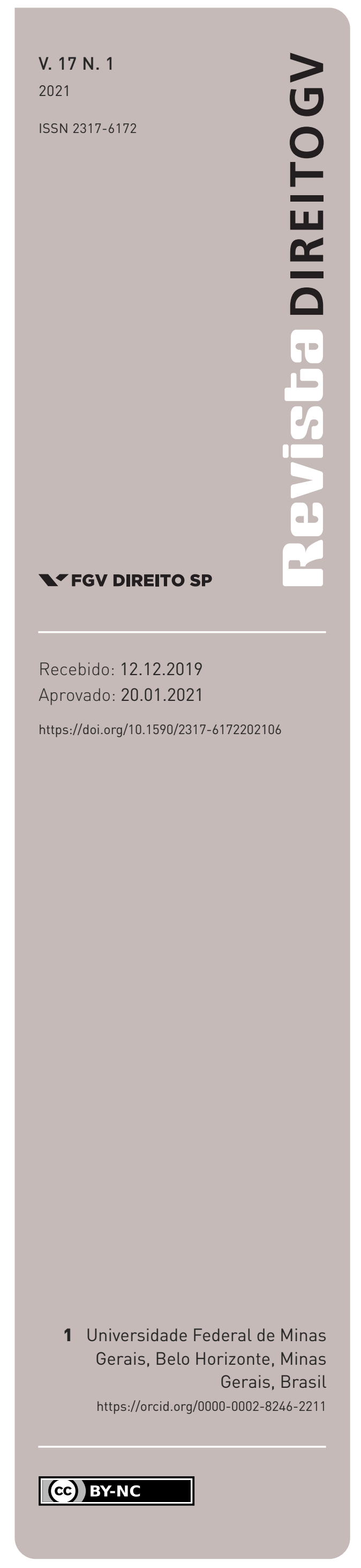

\title{
INTOLERÂNCIA RELIGIOSA NO ESTADO DE MINAS GERAIS: CONSIDERAÇÕES A PARTIR DE UMA PESQUISA COM BOLETINS DE OCORRÊNCIA
}

RELIGIOUS INTOLERANCE IN THE STATE OF MINAS GERAIS: CONSIDERATIONS FROM A RESEARCH BASED ON POLICE REPORTS

\section{Camila Silva Nicácio}

\section{Resumo}

Este artigo se situa na interseção dos campos disciplinares do direito e das ciências sociais e sonda o tratamento institucional da intolerância religiosa no Brasil, particularmente no estado de Minas Gerais. Trata-se de pesquisa empírica que privilegia a análise qualitativa e quantitativa de dados primários, retirados de boletins de ocorrência registrados entre 2016 e 2018, e recorre, principalmente, aos procedimentos da coleta de dados e análise de conteúdo. 0 trabalho restitui os principais resultados de uma pesquisa de pós-doutorado que visou, inicialmente, identificar o modo pelo qual se dá a tradução das demandas baseadas em intolerância religiosa do código social para o código especializado do direito. Objetivo acrescido no processo de investigação foi o de analisar a possibilidade de emergência da intolerância religiosa como um problema público, nos termos desenvolvidos por Daniel Cefaï, em face do tratamento que the é dispensado pelas instituições de segurança pública. Os resultados apontam para dificuldades na referida tradução, suscetíveis de inviabilizar a emergência da intolerância religiosa como um problema público, bem como para a oportunidade de reflexão acerca de outras tecnologias sociais, não jurídicas, para abordar a questão da intolerância.

\section{Palavras-chave}

Direito; religião; intolerância; boletins de ocorrência; problema público.

\begin{abstract}
This paper is located in between the disciplinary fields of law and the social sciences and investigates the institutional treatment of religious intolerance in Brazil, particularly in the state of Minas Gerais. This empirical research privileges the qualitative and quantitative analysis of primary data, taken from police reports registered between 2016 and 2018, and uses mainly the procedures of data collection and content analysis. The work restores the main results of a postdoctoral research that aimed initially to identify how the demands based on religious intolerance from the social code to the specialized code of law are translated. An additional objective in the investigation process was to analyze the possibility of the emergence of religious intolerance as a public problem, under the terms developed by Daniel Cefaï, taking into account the treatment given to it by the institutions, especially the Civil Police. The results point to difficulties in this translation, which may prevent the emergence of religious intolerance as a public problem, as well as the opportunity to reflect on other social technologies, non-legal, to address the issue of intolerance.
\end{abstract}

\section{Keywords}

Law; religion; intolerance; police reports; public problem. 


\section{INTRODUÇÃO}

Como o direito capta e traduz as tensões oriundas de relações sociais marcadas pelo pluralismo religioso, especificamente no que vem sido construído em termos de "intolerância religiosa”, em um contexto em que a contraposição entre religiões inscritas no espaço público sob a ordem da hierarquia e da subcategorização é atuante, a despeito do que prescreve a lei? Como o direito, via seus operadores (escreventes, delegados, policiais militares, policiais civis, advogados, promotores, juízes, etc.), participa da tradução dos conflitos baseados em intolerância religiosa para o código do direito? Nessa tradução, de quais categorias se vale, uma vez que a "intolerância religiosa" não é, em si, um tipo penal propriamente dito, a exemplo da discriminação ou do preconceito religioso, definidos pela Lei n. 7.716/1989, popularmente conhecida como Lei Caó? Como aportam no mundo jurídico, mormente em sua "porta de entrada", as delegacias de polícia, demandas pautadas em intolerância religiosa? Pela intermediação de associações e/ou grupos organizados? Pelas supostas vítimas diretamente? Quem são as vítimas? Quem são os supostos autores? Quais são as religiões mais concernidas por tais violências? Tais dados poderiam testemunhar sobre o nível de organização de diferentes religiões contra a discriminação e o preconceito religiosos? Em que medida as dinâmicas jurídicas de tratamento da ofensa ao pertencimento religioso e à profissão de fé ratificam e reforçam a lógica da marginalização de algumas religiões, em um momento em que elas se apresentam como "relativas entre si" e "em competição pela influência social e primazia na relação com o Estado" (MONTERO, 2015)? Tais dinâmicas implicam circularmente, e, em caso afirmativo, por qual processo, o incremento de práticas intolerantes propriamente ditas?

Referidas indagações compuseram o ponto de partida para uma abordagem empírica da intolerância religiosa no Brasil, centrada particularmente no estado de Minas Gerais, no âmbito de um projeto de pós-doutorado, desenvolvido junto ao Centro Brasileiro de Análise e Planejamento (Cebrap). ${ }^{1}$ Assim como demonstrarei, a perspectiva empírica tratou-se não somente de uma escolha metodológica, mas respondeu à necessidade de suprir as ausências de um campo em que predominam abordagens teóricas, no qual a ação de atores e redes parece não ter merecido até aqui a devida atenção. Olhar para dentro das instituições, no caso que me toca, a Polícia Civil, e desvelar a forma pela qual as demandas baseadas em intolerância religiosa adentram seus fluxos e suas dinâmicas representou o primeiro passo de uma empreitada investigativa que se pretende mais ampla, visando ao acompanhamento e à análise de inquéritos, processos e audiências, notadamente pelo intermédio da inspiração etnográfica. Assim, por ora, cabe-me restituir os elementos centrais de uma pesquisa que chega ao termo de sua primeira fase e, para alcançá-lo, introduzo, para melhor situar

1 Referida pesquisa se inseriu na proposta mais abrangente de um projeto temático intitulado "Religião, direito e secularismo: a reconfiguração do repertório cívico no Brasil contemporâneo”. 
o leitor sobre o tema a ser abordado, (1) um état des lieux do tratamento da intolerância religiosa na produção científica recente, (2) seguido da explicitação da orientação metodológica que a pesquisa observou e (3) dos principais achados e considerações que, como pesquisadora da área jurídica, pude alcançar ao longo da investigação. Concluo este artigo com algumas considerações acerca da relação problemática entre intolerância religiosa e problemas públicos.

\section{A INTOLERÂNCIA RELIGIOSA NA PRODUÇÃo CIENTÍFICA}

A partir de algumas das questões supra elencadas, sondei o tratamento institucional das demandas pautadas em intolerância religiosa em Minas Gerais. Como pesquisadora egressa da área jurídica, percebi que tal investigação me imporia uma tarefa inglória, haja vista a limitação das investigações sobre intolerância religiosa no campo jurídico propriamente dito.

Não é que as relações entre direito e religião tenham passado desapercebidas pelos juristas. Ao contrário, sobretudo para aqueles sociológica, histórica e antropologicamente orientados (cf. ALLIOT, 2003; CARBONNIER, 2008; LEGENDRE, 1989; 2016; ROULAND, s.d.; 1988; SUPIOT, 2005), tais relações relevam da evidência, embora tenham alcançado pouca capilaridade e interesse no conjunto da literatura jurídica. No âmbito das práticas e das instituições, e particularmente referenciando a interface direito e intolerância religiosa, poucos trabalhos podem, no entanto, ser repertoriados que se dediquem à investigação do fenômeno. $\mathrm{Na}$ literatura nacional ganham destaque ao menos quatro iniciativas, distintas cada uma em sua abordagem e todas inscritas no campo das ciências sociais. ${ }^{2}$

Evoco, inicialmente, os trabalhos organizados por Vagner Gonçalves da Silva (2007), em que, também como autor, ele indica inúmeras ocorrências, a que ele chama “ataques", identificadas como intolerância religiosa em São Paulo contra a imagem pública das religiões de matriz afro-brasileira, tais como agressões durante os cultos das igrejas neopentecostais, bem como em seus meios de divulgação (emissoras de rádio, editoras, rede de televisão), agressões físicas em direção aos membros e aos terreiros daqueles grupos e, igualmente, ofensas às cerimônias religiosas afro-brasileiras em espaços públicos diversos. Nessa obra, há restituição de apenas uma análise propriamente jurídica, realizada por Hédio Silva Júnior (2007), ${ }^{3}$ em que

2 Tal como o leitor notará, tais trabalhos se concentram na violência religiosa praticada contra afro-religiosos. Referida concentração não poderá ser problematizada neste espaço, embora não me pareça anódina, sobretudo se observada à luz dos poucos dados disponíveis sobre intolerância religiosa no Brasil de modo geral e dos dados encontrados por esta pesquisa de modo particular.

3 Ex-secretário de segurança do estado de São Paulo, o autor é também advogado e autor, com várias entidades afro-brasileiras, de uma petição na Corte Interamericana de Direitos Humanos (CIDH) dando a conhecer as violações do estado brasileiro na seara da intolerância religiosa. Em entrevista, Silva Júnior 
o autor, para além de apresentar a passagem histórica, da repressão à proteção, do repertório jurídico com relação ao público afrodescendente, situa a intolerância religiosa como crime de discriminação, inafiançável e imprescritível.

Por outro lado, numericamente expressivos e inovadores na análise, destaco os trabalhos de Miranda (2010, 2012, 2014 e 2015), de Miranda, Correa e Almeida (2017), e de Miranda, Correa e Pinto (2017), desenvolvidos no âmbito do Instituto de Estudos Comparados em Administração Institucional de Conflitos (INCT-INEAC) da Universidade Federal Fluminense. Em dez anos de investigação, a agenda de pesquisa dessa autora e coautores parece poder dividir-se em, pelo menos, dois momentos. Os primeiros trabalhos se voltaram à compreensão das dinâmicas pelas quais os afro-religiosos se apresentavam como vítimas de intolerância religiosa, bem como dos meios utilizados para dar visibilidade às suas demandas, como denúncias na mídia, registros em delegacias de polícia e, residualmente, processos judiciais que deles advinham. Nesse momento, encontram-se etnografias dedicadas a sondar o tratamento e a administração institucional de conflitos acerca da intolerância religiosa por parte de agentes do Estado, mormente policiais, promotores, magistrados, conciliadores e mediadores (MIRANDA, 2010 e 2012).

Em um segundo bloco de investigação, pode-se situar a tentativa de identificação e análise das formas pelas quais religiosos afro-brasileiros se organizam no espaço público para a reivindicação de seus direitos de cidadania. A partir de estudos etnográficos, Miranda e coautores sondam as diferentes práticas, operações discursivas e vocabulário de motivações de que se valem aqueles agentes para se legitimarem no espaço público e situarem a intolerância religiosa como um problema público, demandando tratamento adequado por parte dos poderes públicos e das instituições sociais (MIRANDA, 2014 e 2015; MIRANDA, CORREA e ALMEIDA, 2017; MIRANDA, CORREA e PINTO, 2017).

O conjunto dessas análises contribui tanto para confirmar algumas evidências levantadas por trabalhos que as antecederam quanto para contestar outras tantas, abrindo novas pistas de reflexão. Confirma-se, por exemplo, a motivação deliberada de ocupação do espaço público como forma de legitimação da atuação de sujeitos que, histórica e sistematicamente, adentraram e foram vistos pelo sistema de justiça como "réus" (SCHRITZMEYER, 2004), e não como "vítimas", segundo a gramática do direito e do processo penal. Contesta-se, como consequência, a dificuldade ou indisposição dos grupos afro-religiosos de se organizarem politicamente em torno de uma representação coletiva para defesa de seus direitos (SEGATO,

aponta a "necessidade de mobilizar a opinião pública internacional e disponibilizar para os povos de matriz africana mais uma ferramenta na luta em defesa da honra e da dignidade da religião”. Ao que me interessa, há, particularmente, a indicação para a necessidade em se aperfeiçoar o aparato normativo para o tratamento dos crimes de intolerância. Cf. Carta Capital (2017). 
1991), haja vista tanto as contraposições entre diferentes nações quanto a crença nos Orixás como instância privilegiada da "verdadeira justiça”. As etnografias sobre a Comissão de Combate à Intolerância Religiosa (CCIR), foco primeiro das investigações de Miranda, apontam para tal balanço. Igualmente, confirmam a dificuldade de transposição das demandas sociais para o plano jurídico, seja porque o direito, em função de sua técnica, "eufemiza" os conflitos, e por consequência os eventuais danos causados (KANT DE LIMA, 2013), sobretudo os de natureza moral (CARDOSO DE OLIVEIRA, 2002), seja porque, baseado em interpretação, o direito encontra-se à mercê de paixões, disputas, interesses diversos, atuantes quando da definição entre o legal e o ilegal (KANT DE LIMA, 2014). Não é por outra razão que, segundo os resultados de Miranda, o tratamento institucional dos conflitos advindos de práticas de intolerância religiosa tende a ser o de negar e/ou desqualificar as agressões como crime, tratando-as como "picuinha de vizinho", ou algo que deva ficar adstrito à esfera privada, sendo administrado como tal.

Tem-se, ainda, no âmbito de uma dissertação de mestrado, o trabalho de Milton Bortoleto (2014), que irá, a seu turno, demonstrar como um caso ocorrido em 2008 na cidade do Rio de Janeiro contribuiu para a definição da intolerância religiosa como "crime". As principais análises desse trabalho foram também restituídas, em síntese, em Bortoleto (2015). Para além da análise do caso concreto, coube a esse autor uma reconstrução em profundidade da categoria "intolerância religiosa". Baseado em uma vasta bibliografia, Bortoleto (2014) passa em revista mais de duas décadas de reflexão em torno do que veio a ser chamado "conflito entre adeptos de igrejas neopentecostais e os das religiões afro-brasileiras". O autor sistematiza referida produção científica em três fases, descrevendo-as como um movimento de passagem da noção de "guerra santa" àquela de "intolerância religiosa", em que a natureza mesma do conflito se transforma. A primeira, de caráter ensaístico, situa-se ainda nos anos 1980 e tem seu lastro em material jornalístico que, à época, dava conta do aumento exponencial de igrejas pentecostais cujas práticas encorajavam ataques às manifestações de fé das religiões afro-brasileiras, donde a expressão, cunhada naquele momento, "guerra santa". Essa primeira abordagem lançou bases para o desenvolvimento de uma agenda de pesquisa que se encontra em curso até os dias de hoje. Uma segunda fase se baseou no aprofundamento das análises acerca desse novo pentecostalismo, chamado por alguns, a partir de então, neopentecostalismo, que tem na Igreja Universal do Reino de Deus (IURD) sua mais forte expressão, e cujas práticas, lastreadas nos rituais da Libertação do Mal e da Teologia da batalha espiritual, significam maior contraposição às religiões afro-brasileiras. Em terceiro plano, os estudos convergiram para a compreensão de como os afro-brasileiros se comportavam, via organização ou não, em face dos então chamados "ataques" impingidos por seus antagonistas. É nessa terceira fase que a expressão "intolerância religiosa" ganha força como categoria discursiva, não somente pela atuação de grupos e associações militantes, como também pelo envolvimento de setores do sistema de justiça, segundo o que foi demonstrado pelo caso concreto analisado por Bortoleto (2014 e 2015). 
Finalmente, quanto a Nathália Vince Fernandes e Clara Jane Adad, em artigo relativamente recente (2017), há a discussão acerca de um possível deslocamento da noção de "intolerância religiosa" para aquela de "racismo religioso", em que os marcadores cor/raça se sobrepõem ao marcador religião. A partir de uma leitura decolonial e apoiada nos dados do Relatório sobre violência e intolerância religiosa no Brasil (RIVIR), realizado pelo então Ministério de Estado das Mulheres, da Igualdade Racial, da Juventude e dos Direitos Humanos (SDH-PR, 2016), a noção de intolerância religiosa é decomposta pelas autoras, sendo lastreada na empresa colonial na América Latina que, a partir da naturalização e da hierarquização das diferenças, pôde dominar e controlar. As autoras mencionam o racismo como uma "dupla intolerância" religiosa, haja vista a dificuldade em se denunciar e processar os casos de violências e intolerâncias sofridas pela comunidade de religião afro-brasileira, segundo elas "justificadas tanto pela falta de estrutura dos órgãos como do reconhecimento e do acolhimento pelos funcionários que recebem essas denúncias" (2017, p. 14).

Nessa mesma linha de argumentação, em artigo no qual comentam o resultado da votação, pelo Supremo Tribunal Federal (STF), do Recurso Extraordinário (RE) 494601, em que se discutiu a constitucionalidade do abate animal em ritos religiosos, Thiago de Azevedo Pinheiro Hoshino e Winnie Bueno (2019) indagam sobre o possível reconhecimento, por parte daquele STF, do racismo religioso como elemento do racismo estrutural no Brasil. Nas palavras dos autores:

Há anos vem se reivindicando o conceito que, no lugar de sua congênere liberal - a "intolerância religiosa" - demarca "a gravidade e, sobretudo a especificidade da experiência de uma violência perpetrada contra as religiões de matriz africana, que tem no racismo o seu sustentáculo de legitimação e ação destruidora”, posto que as agressões por elas sofridas "não se circunscrevem a um caráter puramente religioso, mas a uma dinâmica civilizatória repleta de valores, saberes, filosofias, cosmogonias, em suma, modos de viver e existir negro-africano amalgamados nas comunidades de terreiro”. (2019, s.n.)

Ainda nesse diapasão, é a mesma Miranda que, em artigo recente publicado na mídia, indaga sobre a correlação entre a intolerância religiosa e o "genocídio do povo preto" (2019). A autora aponta para a violência crescente contra os adeptos das religiões de matriz africana no Rio de Janeiro, segundo uma evolução que migraria da intolerância religiosa ao racismo e, posteriormente, ao genocídio daqueles. Tal gradação já teria sido reconhecida institucionalmente, vide nota técnica do Ministério Público Federal (MPF), em 2018, em que classifica os casos de violência ora como "crimes de ódio" e "racismo religioso", ora como "atos terroristas" ou "genocídio”. Impetrados por adeptos de igrejas neopentecostais ou pela milícia e pelo tráfico de drogas, tais ataques comporiam uma estratégia de domínio de territórios há muito abandonados pelo Estado. Segundo a autora, o avanço de disputas que utilizam os confrontos religiosos tenderia a criar uma "cortina de fumaça" para a dominação dos territórios. Ao indicar o termo 
“narcopentecostalismo" e a prisão de um grupo denominado "Bonde de Jesus", 4 Miranda evoca a relação de tais eventos com a penetração de evangélicos neopentecostais no sistema carcerário. Tais incidências teriam repercussão igualmente em estados como Pará, Amazonas, Alagoas, Bahia, Pernambuco, São Paulo, Sergipe e Rio Grande do Sul. Encarada por especialistas não somente como um problema no campo das disputas religiosas, mas uma questão de segurança pública, tal tendência imporia novas ferramentas e estratégias de intervenção para impedir o ataque cultural e físico à afro-religiosidade no Brasil. ${ }^{\mathbf{5}}$

Mais do que compor uma agenda sólida de pesquisa em antropologia e sociologia das religiões, tais estudos parecem despertar questões cruciais para outros domínios científicos. O direito, no que me ocupa neste trabalho, pode-se valer do adiantado de tais reflexões para sondar como se tem dado a tradução da intolerância religiosa para sua gramática própria, e isso sobretudo em face do "emaranhado normativo" em que as denúncias se enredam e da dificuldade dos agentes em identificarem nas violências relatadas ofensa à liberdade religiosa propriamente dita.

Friso que, por "emaranhado normativo", eu me refiro à miríade de tipificações penais suscetíveis de recobrir violências que têm por alvo o sentimento religioso, a profissão de fé, em síntese, a liberdade de crença e de culto. Podem-se evocar, por exemplo, os arts. 140 e 208 do Código Penal, referindo-se à injúria e ao ultraje a culto e impedimento ou perturbação de ato a ele relativo. Igualmente, encontram-se condutas tais como o constrangimento e a humilhação de crianças em escolas públicas, a recusa de funcionários públicos em atender o público afro-religioso e, ainda, sentenças judiciais que negam o status de religião ao candomblé, à umbanda, ao batuque, entre outros. Somam-se a estes, outros tipos penais, não especificamente voltados à ofensa contra a liberdade religiosa, e, tendentes, possivelmente, a dissimulá-la, tais como agressões físicas envolvendo familiares e/ ou vizinhos, conflitos no ambiente de trabalho e em espaços públicos, como parques, delegacias, tribunais, além de discursos de ódio, terrorismo, tortura, ameaças ou ainda dano ao patrimônio cultural. A tipificação inscrita na Lei n. 7.716/1989, a partir das modificações trazidas pela Lei n. 9.459/1997, segundo as quais é crime inafiançável e imprescritível a prática de discriminação ou preconceito contra religiões, é, finalmente, pouco mobilizada. Parecem confirmá-lo

4 Em artigo recente publicado na mídia, assinado por Terrence McCoy (2019), há referência ao "terror religioso" impingido pelo "Bonde de Jesus" a comunidades de terreiro no Rio de Janeiro.

$5 \quad$ No âmbito deste artigo, assim como veremos a partir da apresentação e da análise dos dados empíricos, não foi possível avançar na correlação entre intolerância e racismo - o que será feito, espera-se, com base em novos dados primários a serem colhidos. Assim, sem que isso signifique um alheamento às discussões que acabo de apresentar e, ao contrário, reconhecendo a plausibilidade do termo "racismo religioso" no contexto brasileiro, a expressão "intolerância religiosa" será aqui privilegiada como gênero, do qual o racismo religioso seria espécie no que toca ao preconceito dirigido aos adeptos das religiões afro-brasileiras. 
as análises feitas por Bortoleto (2014 e 2015), Miranda (2010) e Miranda, Correa e Almeida (2017) no que toca à cidade do Rio de Janeiro.

Em Minas Gerais, estado com o terceiro maior número de registros quanto à intolerância religiosa ${ }^{6}$ no Brasil, não há, como no Rio de Janeiro, uma estrutura nos moldes da CCIR, ${ }^{7}$ e apenas recentemente (2018) foi inaugurada uma Delegacia Especializada de Investigação de Crimes de Racismo, Xenofobia, LGBTfobia e Intolerâncias Correlatas (Decrin), similar à Delegacia de Crimes Raciais e Delitos de Intolerância (Decradi) paulista. Pelos estudos disponíveis e já mencionados, por se tratar de uma delegacia especializada no combate à intolerância religiosa, no caso paulista, e de um grupo religioso heterogêneo que pauta suas ações sobretudo na busca ativa e denúncia das violações, no contexto fluminense, tais estruturas tendem a tornar mais visíveis e tangíveis as demandas acerca da intolerância religiosa, facilitando, inclusive, a sistematização e o controle de dados. Tais diferenças entre os estados, bem como a ausência de estudos análogos e os índices mineiros quanto às ofensas pautadas na intolerância religiosa, justificaram meu interesse em sondar, no contexto daquele estado, a tradução institucional que as narrativas sobre intolerância recebem por parte dos órgãos do sistema de justiça, a contar por sua porta de entrada, os registros de ocorrência policial. Para fazê-lo, procedi da maneira explicitada a seguir.

\section{NotAS METODOLÓGicAS}

A metodologia para a elaboração da pesquisa pautou-se na técnica de pesquisa de campo, mormente a etnografia de documentos (LOWENKRON e FERREIRA, 2014; FERREIRA e LOWENKRON, 2020), recorrendo aos procedimentos do levantamento e da revisão bibliográfica; do levantamento de dados junto aos órgãos de informação da Polícia Civil; bem como

6 Dados obtidos a partir da plataforma Disque 100, criada em 2012 pela Secretaria de Direitos Humanos do Ministério das Mulheres, Igualdade Racial e Direitos Humanos. Registros de 2016 dão conta de um aumento de mais de 70\%, em comparação ao ano anterior, nas ocorrências de violência relacionada à intolerância religiosa (149 em 2014 e 252 em 2015). No ranking dos registros, tínhamos à época São Paulo (37), Rio de Janeiro (36), Minas Gerais (29) e Bahia (23). Cf. Agência Brasil (2016). Dados mais atualizados apontam para um decréscimo com relação aos anos anteriores, embora acusem uma denúncia a cada 15 horas, a maioria delas tendo como vítima os adeptos de religiões de matriz africana. Cf. Rocha (2019).

7 Embora exista, no âmbito do Governo de Minas Gerais, o Comitê de Respeito à Diversidade Religiosa (CDR), responsável por promover o reconhecimento e respeito à diversidade de religião, bem como o enfrentamento à intolerância, tal experiência é substantivamente distinta da experiência carioca. Organização independente, a CCIR foi criada em 2008 pelo babalaô Ivanir dos Santos, reunindo diferentes grupos religiosos, além de integrantes do Ministério Público, das polícias civil e militar, e membros da sociedade civil, com o intuito de, ao mesmo tempo, documentar casos sobre intolerância religiosa e prestar apoio às vítimas, inclusive via denúncia de tais agressões. 
da análise qualitativa e quantitativa de tais dados. A natureza dos dados é majoritariamente primária, além de dados secundários de apoio à análise. A abordagem analítica é interdisciplinar, associando primordialmente antropologia e direito, o que se justifica tendo em vista a insuficiência de análises mono ou unidisciplinares que considerem o direito algo independente ou alheio ao conjunto social mais abrangente (GUSTIN, DIAS e NICÁCIO, 2020).

A partir da estratégia metodológica da pesquisa de campo, a investigação se baseou na análise de documentos, mormente dos Relatórios de Eventos de Defesa Social ${ }^{8}$ (REDS) versando sobre o tema da intolerância religiosa em Minas Gerais, recolhidos junto ao setor de informação da Polícia Civil do Estado (Central de Informação de Defesa Social - CINDS). ${ }^{9}$ Os procedimentos mais recorrentes foram os de levantamento documental, bibliográfico e de dados primários advindos dos referidos REDS, além da análise destes.

Porque não houve até o presente momento sistematização ou controle de dados com relação à intolerância religiosa no estado de Minas Gerais, a delimitação do escopo da investigação, com o objetivo de orientar a extração de dados dos REDS, constituiu-se em parte delicada da pesquisa. Trabalhei a partir de três diferentes vetores, quais sejam, o temporal, o geográfico e o temático, devidamente explicitados e justificados a seguir.

No vetor temporal, foram utilizados dados referentes ao período de janeiro de 2016 a maio de 2018. Foi importante situar a busca em tal intervalo tendo em vista que de 2013 a 2017 se dá a implantação e melhoria do REDS. Referida implantação teve início em 2005 em Belo Horizonte, mas só foi concluída para todo o estado em 2011. Dados recobrindo todo o estado só puderam ser obtidos, assim, a partir de 2012. Contudo, ao longo daquele ano houve um processo de revisão do sistema, em razão da qual foi possível observar mudanças de nomenclatura, além de erros de preenchimento no período de adaptação. Sendo assim, o recorte fixado posteriormente a 2013, data em que o sistema se estabiliza, visou garantir acesso a dados de todos os municípios, evitando inconsistências. ${ }^{10}$

8 Equivalente aos boletins de ocorrência, o REDS é lavrado junto ao Módulo do Sistema Integrado de Defesa Social (SIDS) do Estado de Minas Gerais, destinado ao lançamento de ocorrências (crimes, contravenções, violências, acidentes e violações de direitos em geral) via internet, independentemente da instituição ou do local de registro dos fatos. Esse sistema é acessado por agentes de segurança pública cadastrados por meio de navegador web e consiste em um formulário eletrônico no qual as diversas características do fato são registradas em campos parametrizados, nos quais o usuário seleciona uma das opções constantes em uma lista fechada. Além disso, existe um campo textual denominado "Histórico da Ocorrência", no qual o usuário descreve os fatos. Cf. Governo de Minas (2008).

9 O acesso a tais dados foi franqueado via Acordo de Cooperação Técnica celebrado entre a Universidade Federal de Minas Gerais e a Secretaria de Estado de Segurança Pública do Governo de Minas Gerais (Sejusp), na data de 31 de maio de 2019, publicado no Minas Gerais de 4 de junho de 2019.

10 Esse conjunto de informações foi obtido, no dia 3 de julho de 2018, junto ao Observatório de Segurança Pública Cidadã, da Sejusp. 
No vetor geográfico, foram mobilizados dados de todo o estado, apresentados em número absoluto e em taxa, e estratificando a análise da incidência pelas 11 mesorregiões territoriais. A análise para a região metropolitana de Belo Horizonte foi feita à parte, a fim de evitar distorções, haja vista sua maior densidade populacional.

No vetor temático, contou-se com duas formas complementares de filtragem de ocorrências. A primeira, mais automatizada, consistiu na extração de todos os crimes em que foi utilizada a opção "Intolerância Religiosa” e "Discriminação/preconceito religioso" no campo "Causa ou Motivação Presumida”. A segunda, mais manual, baseou-se na leitura e análise do campo "Histórico", que apresenta um relato textual dos fatos, bem como na busca por palavras-chave naquele campo, ${ }^{11}$ para posterior refiltragem. O objetivo dessa leitura foi verificar a qualidade do preenchimento dos REDS, a partir da comparação entre relato textual e opções utilizadas nos campos parametrizados. Porque não se encontrou, em números absolutos, um total muito elevado de ocorrências (168 registros de fatos ocorridos entre janeiro de 2016 e maio de 2018 que atendiam ao parâmetro supramencionado), as análises puderam ser feitas pelo universo encontrado, e não por amostragem.

Entre os campos existentes na base de dados pesquisada, destacam-se: natureza principal e até três naturezas secundárias do fato; data e hora do fato; tipo de local onde aconteceu o fato; alvo, meio utilizado e causa ou motivação presumida; e histórico da ocorrência. Todas as ocorrências foram analisadas com o objetivo de verificar: (a) a existência (ou não) de um crime ou conflito motivado por intolerância religiosa; (b) a(s) natureza(s) do crime ou conflito motivado por intolerância religiosa (com possibilidade de mais de uma natureza por ocorrência); (c) a existência (ou não) de outra modalidade de intolerância como motivadora da ação dos envolvidos; (d) a religião do envolvido que foi vítima da ação motivada por intolerância religiosa; (e) a relação entre a vítima e o autor da ação motivada por intolerância religiosa; e, finalmente, (f) as palavras-chave que descreviam a ação motivada por intolerância religiosa.

Quanto ao quadro teórico, insiro aqui uma consideração fundamental. Sondar o tratamento institucional da intolerância religiosa, inserida no contexto abrangente de pesquisa do projeto temático "Religião, direito e secularismo: a reconfiguração do repertório cívico no Brasil contemporâneo", não foi uma opção anódina. Ao contrário, minha inserção no grupo implicou,

11 O levantamento inicial identificou 235 palavras-chave, as quais apareciam 435 vezes nos históricos das ocorrências. A partir disso, foi feito um refinamento que conseguiu simplificar esse escopo para 91 palavras-chave, as quais apareciam 487 vezes nos históricos das ocorrências. Como exemplos desse refinamento, destacam-se: a expressão "culto religioso" foi desdobrada em "culto" e "religioso"; da expressão "assembleia de Deus" foi considerada apenas "Deus". Essas 91 palavras-chave foram utilizadas como base para uma segunda solicitação de fornecimento de dados apresentada à Sejusp. Considerações detalhadas sobre a relação entre classificação das ocorrências e palavras-chave podem ser conferidas em Nicácio (2020). 
desde o início, revisão de lugares teóricos e metodológicos que reverberam nos resultados encontrados até aqui. Foi necessário apropriar-me de um instrumental teórico de que não dispunha de saída e, com ele e as inflexões que trazia, aportar ajustes à execução. Nesse domínio, menciono sobretudo a familiaridade adquirida ao longo da execução da pesquisa com autores advindos do pragmatismo francês, mormente Daniel Cefai, cuja noção de "problema público" representou alteração expressiva na abordagem inicialmente pensada.

Meu percurso, pautado predominantemente pela questão do acesso à justiça, seus limites e dinâmicas, tornava previsível, quando não cômoda, a abordagem do problema de pesquisa a partir do ponto de vista de sua institucionalidade: as dificuldades do sistema de justiça em compreender, traduzir e responder às demandas baseadas em intolerância religiosa. A leitura dos pragmatistas opera um tipo de inversão especular em que, mantido o objeto, o foco se altera: pergunto-me, a partir de então, sobre as condições de possibilidade de emergência da intolerância religiosa como problema público, no sentido cefaïano, haja vista o tipo de tratamento que lhe oferece o sistema.

Nesse sentido, a questão inicial sobre "como se dá a tradução do código social para o código do direito das demandas relacionadas à intolerância religiosa pelos mediadores ou tradutores do sistema" se associava a uma outra, a saber, "como o direito, via seus atores e instituições e o que fazem no campo, participa da produção de um problema público (no caso que me ocupa, a intolerância religiosa), seja majorando-o, minorando-o, ou, no limite, embaraçando sua emergência”. Por problema público eu devo entender o que emerge quando as consequências de uma ação são percebidas como extensivas àqueles que não estão diretamente engajados nela (CEFAÏ, 1996; CEFAÏ e TERZI, 2012). Referida perspectiva teórica será novamente evocada mais à frente.

À luz da abordagem e do instrumental metodológicos aqui explicitados, cheguei aos resultados repertoriados a seguir.

\section{O QUE DIZEM OS DADOS: PRINCIPAIS RESULTADOS}

Os dados até aqui obtidos junto ao sistema de segurança pública mineiro me permitem uma série de reflexões, às quais devem se somar, alimentando-os, os próximos passos da pesquisa. Dos primeiros resultados, pude extrair:

1) das 168 ocorrências encontradas, apenas 101 (60\%) foram consideradas típicas, ou seja, indicam a presença de crime ou contravenção penal relacionada a violência e intolerância religiosa;

2) a violência e a intolerância religiosa estão presentes em vários lugares (igrejas, vizinhanças, escolas, locais de trabalho, rua, etc.), ainda que a tônica nos locais que indicam relações de proximidade seja expressiva; 
3) trata-se de violências dirigidas contra várias matrizes religiosas (cristianismo, protestantismo, espiritismo, umbanda, candomblé, etc.), inclusive contra a ausência delas, pois a categoria "ateísmo" também figura no conjunto de dados;

4) religiões de matriz africana são particularmente afetadas (31 casos ou 30,4\% das ocorrências, entre candomblé e umbanda), embora os números absolutos apontem para a predominância da violência contra o cristianismo evangélico (35 casos ou 34,3\%). A análise dos dados percentuais, associada aos dados do IBGE $^{12}$ quanto à presença de cada segmento religioso na sociedade brasileira, indica, no entanto, uma inversão da pirâmide: bem menos numerosos, religiosos afro estão mais expostos à violência;

5) a natureza do tipo penal é voltada, predominantemente, para "agressões verbais", com uma frequência de 117 casos (71,3\%); seguida de "agressões a patrimônio ou símbolo religioso, com 24 ocorrências (14,6\%); de “agressão física à pessoa”, com 19 incidências $(11,6 \%)$; e "conflitos cíveis", com apenas 4 casos $(2,4 \%)$;

6) os principais tipos penais encontrados foram relacionados, em ordem decrescente, a: ameaça; escarnecer de alguém publicamente por motivo de crença ou função religiosa; injúria; difamação; calúnia; impedir ou perturbar cerimônia ou prática de culto religioso; dano ao patrimônio;

7) a maior parte das agressões se dá nas relações de vizinhança (37 casos, representando $36,6 \%$ ) e entre conhecidos (12 casos ou 11,9\%), ainda que as relações familiares (10 9,9\%), laborais $(5-5 \%)$ e escolares $(4-4 \%)$ também estejam representadas;

8) em poucos casos, há associação de intolerância ligada à religião à intolerância ligada à questão racial (3 ocorrências, 3\% do total).

Em tópico próprio, a seguir, cuidarei em detalhe da análise de alguns dos dados anteriormente apresentados.

\section{I. DE QUE SETRATA A “INTOLERÂNCIA RELIGIOSA” PARA O PÚBliCO DE CIDAdÃos?}

Fala-se na mídia e se confirma pelos poucos dados oficiais: a "intolerância religiosa" tem crescido no Brasil. É isso o que se depreende da sequência dos números do Disque 100, principal

12 Enquanto evangélicos somaram 22,2\% no Censo de 2010, adeptos da umbanda e do candomblé responderam por apenas 0,3\% do quadro total (IBGE, 2010). 
fonte institucional para capturar e sistematizar dados acerca do tema, e segundo o qual tem-se a seguinte progressão, em número de denúncias por ano: 2011 (15); 2012 (109); 2013 (231); 2014 (149); 2015 (556); 2016 (759); 2017 (537); e 2018 (506). ${ }^{13}$

Referido aumento é confirmado em outras sondagens, tais como a realizada pela Pew Foundation (Latest Trends in Religious Restrictions and Hostilities, 2015), na qual o Brasil saltou posições, passando da posição de um dos 25 países mais populosos com menor taxa $(0,0$ a 1,0) por motivos religiosos em 2007, para um dos países com alta taxa em 2013 (3,5 a 7,0). Frisa-se que os últimos números ainda situam o Brasil como um país relativamente pouco violento em relação às religiões.

Outros diagnósticos, baseados em fontes diversas, chegaram a constatações semelhantes. Destaca-se aqui o já mencionado RIVIR (SDH-PR, 2016), que se concentrou em notícias na mídia escrita nacional, em dados oriundos de ouvidorias governamentais e, por fim, em processos judiciais versando sobre intolerância religiosa no âmbito nacional entre 2015 e 2016.

Ou seja, apesar da imprecisão e eventual sobreposição de dados, das dificuldades identificadas na coleta destes e de sua presumível subnotificação, tudo indica que a "intolerância religiosa" está de fato aumentando no país, embora se situe em patamares acanhados em termos numéricos, considerando-se outras expressões e manifestações de violência contra direitos fundamentais, tais como estupros e homicídios, segundo o último Atlas da violência (IPEA, 2019).

A despeito desse aumento, e do movimento de alguns grupos para dar visibilidade a ele, temos que sublinhar, pela consideração quantitativa e qualitativa dos dados mineiros, que, se de um lado os números são relativamente baixos (101 ocorrências típicas em 2 anos e 4 meses), por outro, o fenômeno é percebido de maneiras muito distintas, sem que se aponte para um núcleo duro, em que ele se defina e se reconheça, tal como apontado pela leitura em detalhe das ocorrências. No que diz respeito aos dados quantitativos, tratarei a seguir. Aqui vale uma nota sobre uma questão qualitativa acerca deles.

Em que medida esses dados estariam relacionados, se estivessem? Haveria conexão entre a relativa baixa incidência de violência ligada à intolerância religiosa e um relativo desconhecimento sobre o que ela abarca e significa, assim como faz supor a análise quantitativa e qualitativa? Seria a existência de inúmeras e diversas naturezas de crime ou conflito na origem desse desconhecimento e/ou confusão aparentes? Como afirmei, foram encontradas nas denúncias nada menos de vinte naturezas de supostos crime ou conflito motivados por intolerância religiosa, posteriormente, e por motivo didático, agrupadas em quatro categorias (agressões

13 Dados obtidos junto ao Ministério da Mulher, da Família e dos Direitos Humanos (MMFDH), via Lei de Acesso à Informação (LAI). 
verbais; agressões a patrimônio ou símbolo religioso; agressão física à pessoa; e conflitos cíveis). Nesse "emaranhado normativo", encontram-se alegações de violências de várias ordens, cujos bens violados são a integridade física e o patrimônio aqui, a honra e a liberdade acolá, aos quais o sentimento religioso parece se amalgamar não como ator principal, mas como coadjuvante. São essas apenas primeiras impressões de algo que merece ser mais bem avaliado e que consiste na percepção, não só institucional, mas social, de que se trata a liberdade e o pluralismo religiosos de algo considerado "menor" ou "acessório”. Irei avançar a seguir nessa linha de análise, embora me valendo de outros argumentos.

Por outro lado, finalmente, já foi evocada supra a existência de uma frente discursiva formada por militantes, grupos religiosos de matriz africana, advogados, intelectuais e acadêmicos, que reivindica a expressão "intolerância religiosa" como forma, ao mesmo tempo, de denúncia e de prevenção contra os “ataques" sofridos por alguns setores. Tais grupos agem sobretudo na cidade do Rio de Janeiro, pelo intermédio de uma CCIR, já largamente estudada pela literatura especializada (MIRANDA, CORREA e ALMEIDA, 2017). Ocorre que, no cenário mineiro, em que esse tipo de comissão não existe, e isso é demonstrado pelos números e relatos encontrados no campo, trata-se de expressão de alcance limitado quanto ao público de reclamantes, uma vez que este mobiliza preferencialmente vocábulos como "discriminação", "preconceito" ou "violência”. De fato, a expressão "intolerância religiosa” incide em apenas 14 de um total de 168 ocorrências, das quais 101 representaram o universo de ocorrências típicas sobre o qual trabalhei.

Tal como afirmado anteriormente, o campo ainda não permitiu avançar na correlação entre racismo e intolerância religiosa, o que merecerá futuras análises, a partir de novos dados. A essa questão voltarei mais à frente.

\subsection{PAdrão de PREenChimento E A EMERGÊNCIA dA "INTOLERÂNCiA Religiosa" COMO UM PROBLEMA PÚBLICO}

Com base no preenchimento dos registros de ocorrência, mormente no que lhe falta como informação, afirmo que seria razoável considerar a impressão seguinte, a partir da leitura dos REDS: pode haver, tendencialmente, a subclassificação dos conflitos relacionados à intolerância religiosa como um problema de menor importância. Resultado semelhante foi encontrado no Rio de Janeiro, quando de pesquisas realizadas por Miranda (2010, 2012, 2014 e 2015), por Miranda, Correa e Almeida (2017), e por Miranda, Correa e Pinto (2017), praticamente os únicos até o momento a cuidar no Brasil do tratamento institucional da intolerância religiosa.

Nota-se, em alguns dos dados, falta flagrante de informações essenciais para uma investigação posterior, se se leva em conta o fato de que inquéritos carecem de um mínimo de informações para determinar uma linha de investigação. Pergunta-se, o destino de boa parte dos REDS não seria a inutilização? Quantos deles embasariam inquéritos, ao seu turno, precocemente arquivados por falta de elementos mínimos? Refiro-me aqui, por exemplo, a dados como a relação entre as vítimas, ou a religião delas, ou às características 
centrais da própria situação pretensamente ofensiva relatada. A seguir, exemplos do que estou indicando:

Caso 1: Comparece a esta Depol a vítima ${ }^{14}$ alegando que, constantemente, vem sendo ameaçada e agredida verbalmente pelos moradores do apartamento 03, onde funciona uma república. Relata a vítima que, no final do ano passado, precisou cortar um varal que havia sido colocado na janela de sua residência pelos moradores do tal apartamento. Alega a vítima que, além das ameaças proferidas contra a sua integridade física, os moradores agem com intolerância religiosa. A vítima informa que está com receio e medo dos moradores do imóvel supracitado e que por tal motivo solicita providências. Ressalta a vítima que estava no telefone, conversando com um cliente, e que em um momento de descontração fez uma brincadeira com o seu cliente e que os moradores do apartamento se sentiram ofendidos e chamaram a polícia militar para a vítima. Assim sendo, registra-se para fins futuros.

Caso 2: A vítima, que está hospedada no local X, comparece a esta delegacia para informar que está sendo ameaçada de morte por um indivíduo negro, magro, de estatura mediana, que mora no mesmo local $\mathrm{X}$.

Caso 3: Compareceu a este Quartel PM, a vítima X, a qual nos relatou o seguinte: Que devido a um encontro religioso que será realizado em sua residência na data de 27/10/2017 a 29/10/2017, está sofrendo ameaças via telefone, onde o autor das ameaças relata que vai acabar com o evento e a pessoa conhecida religiosamente como "luz de Deus", "luz de Deus" se trata de uma pregadora da fé cristã.

Caso 4: Compareceu à sede da Cia 133 de Polícia Militar a vítima Y, e segundo ela foi vítima de ameaça por parte das seguintes pessoas: Envolvida 1 (sogra), Envolvida 2 (cunhada); Envolvida 3 (sobrinha do marido). Com os seguintes dizeres contra a vítima: "Que se ela não saísse da casa que elas iriam puxá-la pelos cabelos", "Que assim que ela colocasse os pés na rua, que iriam bater nela até que ela desmaiasse e rachar sua cabeça". Além de ofensas verbais como: "Vagabunda!"; "Piranha”, ... "E que a filha não é filha do esposo”. Essas ofensas verbais são desferidas também pelas seguintes pessoas: Envolvida 4 (sobrinha); Envolvida 5 (sobrinha); Envolvida 6 (sobrinha) e Envolvida 7 (tia). Este fato se deu na data de hoje, 17/07/2016, por volta das 18:30 e a vítima estava no interior so aos dados, dissimulo aqui todo elemento suscetível de identificação dos envolvidos. 
da sua residência. A vítima informa ainda que não tem outro lugar para morar, caso contrário já o teria feito para evitar esses desentendimentos. A vítima conta ainda que além dela residem na residência o marido, Sr. W, 41 anos (filho, irmão e tio) respectivamente das autoras da ameaça; e também a filha do casal de apenas 3 anos de idade, que inclusive está doente nesses últimos dias.

Caso 5: Acionados via Copom, deslocamos ao Distrito de São João da Chapada, onde segundo a vítima, quando se encontrava na companhia de seu filho, fez um comentário pessoal sobre a religião de seu cunhado, Envolvido 1, com isso Envolvido 1 iniciou um atrito verbal com a vítima, desta forma, no local já com os ânimos acalmados, ambos foram orientados e a ocorrência resolvida no local.

Caso 6: Em contato com o solicitante, ele narrou que se encontrava no endereço retro citado e lá compareceu o Envolvido 1; por motivos fúteis os envolvidos entraram em atrito verbal e iniciaram uma acalorada discussão, chegando a trocar empurrões entre eles; foram orientados quanto às demais providências. Registrado este para futuros fins.

Caso 7: Compareceu na sede da $32^{\mathrm{a}} \mathrm{Cia} \mathrm{PM}$ a vítima juntamente com sua representante legal relatando que vem sofrendo bullying frequentemente no ambiente escolar, tal situação se resulta por sua crença religiosa e aparência física. Ainda segundo a genitora da vítima, esse fato ocorre há bastante tempo, contudo ela, achando que poderia cessar, nunca havia tomado providências, no entanto essa situação está atrapalhando o andamento escolar em sua filha menor e afetando também o estado psicológico da aluna. Diante dos fatos narrados, orientamos a genitora a realizar representação na Depol para providências inerentes ao fato. Diante do exposto, realizamos este para vosso conhecimento.

Considere-se que a instauração de inquérito policial é, pelo menos do ponto de vista teórico, obrigatória diante da presença de elementos mínimos de informação ou de provas que possibilitem o desenvolvimento de uma investigação. O que dizer sobre a visibilidade ou a consistência da intolerância religiosa como um problema público, no sentido cefaïano, que mereça a intervenção estatal? Como um problema que, longe de dizer respeito apenas aos diretamente envolvidos, relaciona-se intrinsecamente com questões mais amplas como a ordem social e o pluralismo? Ainda, o que dizer sobre o impacto do preenchimento no âmbito da elaboração de políticas públicas de enfrentamento à questão?

Obviamente, trata-se de uma impressão inicial, advinda da leitura dos registros, e ainda carente de confirmação. A hipótese, contudo, não deixa de ser plausível: as instituições de polícia e de justiça, aqui confundidas, via seus atores, podem contribuir para modular a questão da intolerância religiosa como um problema público, a princípio, minorando sua importância. Quando falo em instituições, evoco o papel mediador que estas detêm entre a linguagem 
social em que os conflitos normalmente emergem e a linguagem especializada do direito, pela qual cidadãos têm a pretensão de verem protegidos bens jurídicos diferentemente considerados e valorados.

Considera-se plausível que, segundo o que apontaram Miranda e coautores para o caso fluminense, conflitos baseados em intolerância religiosa sejam hierarquizados como problemas menores em um contexto em que, alega-se, ainda que os dados não sejam claros nesse sentido, a taxa de elucidação de crimes tidos como gravíssimos, vide homicídio, é muito baixa. ${ }^{15}$ Referidos conflitos relacionados à intolerância religiosa incidem em um cenário de saturação institucional, em que as instituições tendem a proteger de modo seletivo os direitos. Ao lado de tal saturação parecem operar dinâmicas de "eufemização" de conflitos e danos (KANT DE LIMA, 2013), sobretudo os de natureza moral (CARDOSO DE OLIVEIRA, 2002), e sua consequente "privatização", assim como mencionei anteriormente.

Trabalho coassinado por Marta Machado, Márcia Lima e Nathália Néris (2016) já havia apontado para essa mesma direção, qual seja, a dificuldade de o sistema de justiça traduzir um acontecimento, no caso das autoras, as injúrias raciais, como crime que mereça punição organizada pelo Estado. A questão da invisibilização de algumas ofensas, aqui a intolerância religiosa, acolá a injúria racial, parece, assim, recolocar, atualizando-a, a discussão sobre a proteção de bens jurídicos em um momento de forte juridicização e judiciarização ${ }^{16}$ das relações sociais, em que a máquina estatal é solicitada por atores chancelados a participar do debate público - e nele fazer valer seus direitos - no marco do pluralismo inaugurado pela Carta de 1988. Se a invisibilização ou o impedimento da emergência da intolerância religiosa como um problema público não pode, até aqui, ser afirmada categoricamente, os primeiros dados parecem indicar para uma tensão entre a pretensão normalizadora e reguladora do direito e a capacidade e o interesse das instituições competentes em tratar com igual respeito e consideração as demandas ancoradas no pluralismo social.

\section{3•3. NATUREZA PREDOMINANTE DA RELAÇÃO ENTRE AGRESSORES E VÍTIMAS E ALTERNATIVAS PARA INTERVENÇÃO}

A questão discutida anteriormente desperta atenção também para a pertinência e/ou necessidade do tratamento necessária e unicamente jurídico dos conflitos baseados em intolerância

15 O dado é de difícil rastreamento. Contudo, estimativas dão conta de que a cada cem homicídios no Brasil apenas oito são devidamente apurados, englobando autoria e circunstâncias do crime. Cf. Bruno (2011).

16 O termo "juridicização" faz referência à "extensão do direito e de seus processos jurídicos a um número crescente de domínios da vida econômica e social [...]”, cf. Arnaud et al. (1988, p. 319). Por sua vez, "judiciarização" designa “a extensão do papel da Justiça como instituição no tratamento de 'problemas de sociedade', dos quais alguns implicam o campo político, e para os quais a Justiça não era solicitada no passado ou sobre os quais ela não vislumbrava intervir”, cf. Commaille (2002, p. 1, tradução minha). 
religiosa, e a eventual complementaridade advinda de outras instâncias de regulação social para tal enfrentamento, haja vista que o direito não possui o monopólio dessa regulação. Abordarei o tema brevemente neste tópico.

Dados oriundos sobretudo da relação entre vítima e agressor deixam entrever relação de proximidade, quando não de parentesco e vizinhança, entre as partes envolvidas. Pergunta-se aqui sobre a oportunidade e adequação em se investir em abordagens que, ao intervirem preventivamente, não repitam padrões apenas baseados em políticas de segurança pública. Evoco aqui ações que não orbitem apenas nas esferas policial e jurídica, haja vista a patente limitação que elas oferecem. Ainda no âmbito das políticas públicas, parece merecer consideração a busca por iniciativas voltadas, preferencialmente, à pedagogia, ao lazer, ao usufruto de espaços coletivos e inclusivos, em que o intercâmbio entre as diversidades possa ter lugar. Para isso, é necessário enfrentar o que Gusfield (apud CEFAÏ e TERZI, 2012, p. 26) chamou de a “autoridade dos problemas públicos” que, geralmente, impõe às políticas públicas hipóteses, categorias e rotinas que as tornam cegas a soluções alternativas. Vislumbrar a intervenção e o tratamento institucionais das demandas pautadas em intolerância religiosa via, apenas ou preferencialmente, saída policial/judicial ilustra o pensamento do autor. Nesse contexto, ganha relevo a questão sobre a presença e o diálogo do Estado com atores sociais, em fóruns e espaços dedicados ao tema (escolas, comissões, sindicatos, associações, etc.), e ações que, sem descurar da importância da abordagem institucional legal, não depositem nela a chave-mestra para tratar de conflitos que relevam do convívio cotidiano, no qual a complexidade e a diversidade são as características predominantes.

\section{3·4 A INTOLERÂNCIA COMO EPIFENÔMENO DO RACISMO}

Como afirmado supra e confirmado por todos os dados, oficiais ou não, disponíveis até o momento, o público afro-religioso é o mais atingido pelas manifestações de intolerância religiosa. O que se encontrou no contexto mineiro não foi diferente. Em alguns lugares no Brasil, tais manifestações ganham a dimensão de verdadeiros dramas sociais, a exemplo do que se passa no Rio de Janeiro.

Embora a relação entre intolerância religiosa e racismo careça ser afinada em pesquisas posteriores, é inafastável a consideração de que, embora protegidos formalmente pela liberdade e pluralismo religiosos almejados pelo marco constitucional de 1988, várias religiões presentes no Brasil, e de maneira marcante aquelas de matriz africana, parecem estar longe de gozarem de prestígio, respeito e reconhecimento social. Ao contrário, permanecem marginalizadas e perseguidas, embora o tempo monárquico ou ainda o da primeira república sejam remotos. Aumentam os números de “ataques” e crescem, igualmente, as narrativas de "satanização", em que as religiões afro precisam ser "combatidas", pois encarnam o "mal”. Essa dinâmica é há anos fartamente desvelada pelas ciências sociais brasileiras e estrangeiras (SOARES, 1990 e 1993; MARIANO, 2007; ORO, 2007; PLAIDEAU, 2007 e 2009; PIERRE-JOSEPH e PLAIDEAU, 2010) e parece apontar para a necessidade de enfrentamento 
por parte do poder público e da sociedade civil, com complementaridade de estratégias e, sobretudo, com compromisso com a liberdade e o pluralismo religiosos caros à Constituição cidadã.

Ressalta-se aqui a violência específica a que estão submetidas as religiões de matriz-africana por sua alta representatividade no conjunto dos dados e pelo problema particular com o qual ela parece se relacionar, qual seja, o racismo. Isso não significa, no entanto, desatenção ao fato segundo o qual o sentimento religioso tem sido alvo de desrespeito no que tange ao conjunto das religiões observadas no trabalho, e ainda à ausência delas, uma vez que o ateísmo também está representado no universo investigado, ainda que timidamente (1 caso no conjunto dos dados, apenas). Aliás, quanto a essa questão e sua relação com o problema inicialmente colocado, acredito poder afirmar que o descaso para com o tratamento dos dados na "porta de entrada" do sistema de segurança pública é suscetível de aportar consequências consideráveis para a emergência e visibilização de questões relacionadas à intolerância não somente contra afro-religiosos, mas contra religiosos tout court.

\section{CONCLUSÃo}

Algumas considerações alinhavam minha reflexão até que novos dados se somem aos até aqui analisados e deem substância, ratificando ou não, o que pude observar até o momento. Como afirmei inicialmente, a presente análise é apenas um ponto de partida de uma investigação mais ampla, que pretende levar em conta todo o circuito policial e judicial acerca das demandas baseadas em intolerância religiosa. Isso porque, a considerar a observação dos pragmatistas, no que me inspira aqui, Daniel Cefaï, sobre a importância da nomeação na definição da natureza do problema público e na orientação da ação, considero relevante sondar, nos próximos passos desta pesquisa, a ação dos atores do direito para o desenvolvimento do fenômeno. Assim, penso que o tratamento contínuo e anual dos dados oriundos dos REDS mereça ser empreendido, para que se localizem, ao final, igualmente, padrões de desdobramento processual das ocorrências, haja vista que todos os registros são, a princípio, enviados automaticamente à autoridade de polícia judiciária e que a natureza da maioria das infrações impõe seu processamento em juizados especiais criminais. Reafirmo, por outro lado, que a alegada relação entre qualidade dos dados e invisibilização de demandas pautadas em intolerância religiosa como um problema público deve ser objeto de necessário aprofundamento de análise quando da obtenção de novas levas de dados. Sem que isso soe paradoxal, afirmo também que eventual reação organizada dos poderes públicos contra a violência ao sentimento religioso e à profissão da fé, a partir, por exemplo, da criação de estruturas especializadas na abordagem específica da intolerância religiosa, tende a ser aperfeiçoada por estratégias que levem em conta o perfil dos envolvidos, sobretudo em face da relação de proximidade entre eles. 


\section{AGRADECIMENTOS}

A autora agradece à Fundação de Amparo à Pesquisa do Estado de São Paulo (Fapesp) pelo apoio à pesquisa que originou este artigo. A pesquisa se inscreve no âmbito do projeto temático "Religião, direito e secularismo: a reconfiguração do repertório cívico no Brasil contemporâneo”.

\section{REFERÊNCIAS}

AGÊNCIA BRASIL. Denúncias de discriminação religiosa aumentam 70\% no país, revela Disque 100. 21 jan. 2016. Disponível em: http: / / agenciabrasil.ebc.com.br/direitos-humanos/noticia/2016-01/ denuncias-de-descriminacao-religiosa-sobem-70-no-brasil-mostra. Acesso em: 18 nov. 2019.

ALLIOT, Michel. Le droit et le service public au miroir de l'anthropologie. Textes choisis et édités par C. Kuyu. Paris: Karthala, 2003.

ARNAUD, André-Jean et al. (dir.). Dictionnaire encyclopédique de théorie et de sociologie du droit. Paris: L.G.D.J; Bruxelles: Story-Scientia, 1988.

BORTOLETO, Milton. "Não cultuais imagens de escultura”: alguns aspectos do debate público acerca da tipificação jurídica da "intolerância religiosa" e da "liberdade religiosa". In: MONTERO, Paula (org.). Religiões e controvérsias públicas: experiências, práticas sociais e discursos. Campinas: Editora Unicamp, 2015. p. 127-162.

BORTOLETO, Milton. "Não viemos para fazer aliança”: faces do conflito entre adeptos das religiões pentecostais e afro-brasileiras. Dissertação (Mestrado em Antropologia Social) - Faculdade de Filosofia, Letras e Ciências Humanas da Universidade de São Paulo, São Paulo, 2014.

BRUNO, Cássio. Apenas quatro mil dos cerca de 50 mil homicídios cometidos por ano no país são resolvidos. O Globo. 3 nov. 2011. Disponível em: https://oglobo.globo.com/politica/apenas-quatromil-dos-cerca-de-50-mil-homicidios-cometidos-por-ano-no-pais-sao-resolvidos-2773316. Acesso em: 17 fev. 2021.

CARBONNIER, Jean. La religion, fondement du droit? In: CARBONNIER, J. Écrits. Paris: PUF, 2008. p. $1518-1524$. 
CARDOSO DE OLIVEIRA, Luís R. Direito legal e insulto moral: dilemas da cidadania no Brasil, Quebec e EUA. Rio de Janeiro: Relume Dumará, 2002.

CARTA CAPITAL. Um jurista contra a intolerância religiosa. 27 out. 2017. Disponível em: https:// www.cartacapital.com.br/blogs/dialogos-da-fe/um-jurista-contra-a-intolerancia-religiosa. Acesso em: 8 dez. 2019.

CEFAÏ, Daniel. La construction des problèmes publics. Définitions de situations dans des arènes publiques. Réseaux, v. 14, n. 75, p. 43-66, 1996. Le temps de l'événement I.

CEFAÏ, Daniel; TERZI, Cédric (dir.). L'expérience des problèmes publics. Paris: École des Hautes Études en Sciences Sociales, 2012.

COMMAILLE, Jacques. La judiciarisation. Une nouvelle économie de la légalité face au social et au politique? Note de bilan d'étape du groupe "Judiciarisation de la société et du politique". Paris: CERAT, 17 février 2002.

FERNANDES, Nathália Vince E.; ADAD, Clara Jane C. Intolerância ou racismo religioso: discriminação e violência contra religiões de matriz africana. Intolerância Religiosa, v. 2, n. 1, p. 2-17, jul./dez. 2017.

FERREIRA, Letícia; LOWENKRON, Laura (org.). Etnografia de documentos: pesquisas antropológicas entre papéis, carimbos e burocracias. Rio de Janeiro: Faperj, 2020.

GOVERNO DE MINAS GERAIS. REDS - Registro de Eventos de Defesa Social. Maio, 2008. Disponível em: http:/ / www.seguranca.mg.gov.br/component/gmg/page/356-integra\%C3\%A7\%C3\%A3o. Acesso em: 13 out. 2019.

GUSTIN, Miracy B. S.; DIAS, Maria Tereza F.; NICÁCIO, Camila S. (Re)pensando a pesquisa jurídica. São Paulo: Almedina, 2020.

HOSHINO, Thiago de Azevedo Pinheiro; BUENO, Winnie. RE 494601: o reconhecimento do racismo religioso? 2019. Disponível em: http://www.jusdh.org.br/2019/04/04/re-494601-o-reconhecimentodo-racismo-religioso/. Acesso em: $10 \mathrm{dez} .2019$.

INSTITUTO BRASILEIRO DE GEOGRAFIA E ESTATÍSTICA (IBGE). Censo 2010: número de católicos cai e aumenta o de evangélicos, espíritas e sem religião. 2010. Disponível em: https://censo2010.ibge. gov.br/noticias-censo?id=3\&idnoticia $=2170 \& v i e w=$ noticia. Acesso em: $10 \mathrm{dez} .2019$. 
INSTITUTO DE PESQUISA ECONÔMICA APLICADA (IPEA). Atlas da violência. 2019. Disponível em: https://www.ipea.gov.br/atlasviolencia/publicacoes/50/atlas-da-violencia-2019. Acesso em: 17 fev. 2021.

KANT DE LIMA, Roberto. Igualdades jurídicas, transgressões e moralidades: princípios de controle burocrático em uma perspectiva comparada. In: FELDMAN-BIANCO, Bela (org.). Desafios da antropologia brasileira. Brasília: ABA, 2014.

KANT DE LIMA, Roberto. Sensibilidades jurídicas, moralidades e processo penal: tradições judiciárias e democracia no Brasil contemporâneo. Revista de Estudos Criminais, v. 11, n. 48, p. 7-34, 2013.

LEGENDRE, Pierre. L'animal humain et les suites de sa blessure. Paris: Fayard, 2016.

LEGENDRE, Pierre. Le crime du caporal Lortie. Traité sur le Père. Paris: Fayard, 1989.

LOWENKRON, Laura; FERREIRA, Letícia. Anthropological perspectives on documents: ethnographic dialogues on the trail of police papers. Vibrant - Virtual Brazilian Anthropology, Brasília, ABA, v. 11, n. 2, jul./dez. 2014. Disponível em: http: / /www.vibrant.org.br/issues/v11n2/laura-lowenkron-leticiaferreira-anthropological-perspectives-on-documents-ethnographic-dialogues-on-the-trail-of-police-pa pers/. Acesso em: 17 fev. 2021.

MACHADO, Marta R.; LIMA, Márcia; NÉRIS, Nathália. Racismo e insulto racial na sociedade brasileira, dinâmicas de reconhecimento e de invisibilização a partir do direito. Novos Estudos, Cebrap, São Paulo, v. 35, n. 3, p. 11-28, nov. 2016.

MARIANO, Ricardo. Pentecostais em ação: a demonização dos cultos afro-brasileiros. In: SILVA, Vagner Gonçalves da (org.). Intolerância religiosa: impactos do neopentecostalismo no campo religioso afro-brasileiro. São Paulo: Edusp, 2007. p. 119-148.

MCCOY, Terrence. Neopentecostais armados atormentam minorias religiosas brasileiras. 12 dez. 2019. Folha de S.Paulo. Disponível em: https: / /www1.folha.uol.com.br/cotidiano/2019/12/neopentecostaisarmados-atormentam-minorias-religiosas-brasileiras.shtml. Acesso em: 17 fev. 2021.

MIRANDA, Ana Paula Mendes de. Intolerância religiosa ou genocídio do povo preto? 2019. Disponível em: https://blogs.oglobo.globo.com/ciencia-matematica/post/intolerancia-religiosa-ou-genocidiodo-povo-preto.html. Acesso em: 10 dez. 2019.

MIRANDA, Ana Paula Mendes de. The Rebirth of Religious Intolerance: Controversies Regarding State Secularisation in Rio de Janeiro. In: RESENDE, José Manuel; MARTINS, Alexandre Cotovio (ed.). The Making of the Common in Social Relations. [S. 1.]: Cambridge Scholars Publishing, 2015. p. 115-128. 
MIRANDA, Ana Paula Mendes de. Como se discute religião e política? Controvérsias em torno da luta contra a intolerância religiosa no Rio de Janeiro. Comunicações do ISER, Rio de Janeiro, v. 69, p. 10-23, 2014.

MIRANDA, Ana Paula Mendes de. A força de uma expressão: intolerância religiosa, conflitos e demandas por reconhecimento de direitos no Rio de Janeiro. Comunicações do ISER, Rio de Janeiro, n. 66, ano 31, p. 60-73, 2012.

MIRANDA, Ana Paula Mendes de. Entre o privado e o público: considerações sobre a (in)criminação da intolerância religiosa no Rio de Janeiro. Anuário Antropológico, v. 2009-2, p. 125-152, 2010.

MIRANDA, Ana Paula Mendes de; CORREA, Roberta de Mello; ALMEIDA, Rosiane Rodrigues. Intolerância religiosa: a construção de um problema público. Revista Intolerância Religiosa, Rio de Janeiro, v. 2, p. 1-19, 2017.

MIRANDA, Ana Paula Mendes de; CORREA, Roberta de Mello; PINTO, Vinicius C. Conciliação no papel: o tratamento dado aos casos de intolerância religiosa em Juizados Especiais Criminais no Rio de Janeiro. Confluências - Revista Interdisciplinar de Sociologia e Direito, v. 18, p. 21-43, 2017.

MONTERO, Paula. Sincretismo e pluralismo na reconfiguração da diversidade religiosa no Brasil. USP/ Cebrap, 2015.

NICÁCIO, Camila S. A formalização da intolerância religiosa em registros policiais: retrato de um problema em (des)construção. Contemporânea - Revista de Sociologia da UFSCar, Dossiê Religião e Direitos Humanos, v. 10, n. 2, p. 557-583, maio/ago. 2020.

ORO, Ari Pedro. Intolerância religiosa iurdiana e reações afro no Rio Grande do Sul. In: SILVA, Vagner Gonçalves da (org.). Intolerância religiosa: impactos do neopentecostalismo no campo religioso afro-brasileiro. São Paulo: Edusp, 2007. p. 29-69.

PIERRE-JOSEPH, Laurent; PLAIDEAU, Charlotte. Pentecôtismes et néo-pentecôtismes: des religions de l'accumulation? Revue Théologique de Louvain, 41 année, fasc. 2, p. 208-242, 2010. Disponível em: http: / / www.persee.fr/doc/thlou_0080-2654_2010_num_41_2_3826. Acesso em: 17 fev. 2021.

PLAIDEAU, Charlotte. Le néopentecôtisme brésilien: sectes ou croyances à la dérive? Larevuenouvelle, n. 6-7, juin-juillet 2007.

PLAIDEAU, Charlotte. La guerre néopentecôtiste contre le démon afro-brésilien. Civilisations [En ligne], 55, 2006. Disponível em: https://journals.openedition.org/civilisations/252. Acesso em: 17 fev. 2021. 
ROCHA, Camilo. Como a intolerância religiosa tem se manifestado no Brasil. Nexo Jornal, 11 fev. 2019. Disponível em: https: / /www.nexojornal.com.br/expresso/2017/10/11/Como-a-intoler\%C3\%A2nciareligiosa-tem-se-manifestado-no-Brasil. Acesso em: 17 fev. 2021.

ROULAND, Norbert. Anthropologie juridique. Paris: PUF, 1988.

ROULAND, Norbert. Sur la terre comme au ciel. Religion et société en Nouvelle-Calédonie et en Océanie. S.1., s.n., s.d. p. 63-71.

SCHRITZMEYER, Ana Lúcia P. Sortilégios de saberes: curandeiros e juízes nos tribunais brasileiros. São Paulo: Instituto Brasileiro de Ciências Criminais, 2004.

SECRETARIA ESPECIAL DE DIREITOS HUMANOS (SDH). Relatório sobre intolerância e violência religiosa no Brasil (2011-2015): resultados preliminares. Ministério das Mulheres, da Igualdade Racial, da Juventude e dos Direitos Humanos. Alexandre Brasil Fonseca e Clara Jane Adad (org.). Brasília: Secretaria Especial de Direitos Humanos, SDH-PR, 2016.

SEGATO, Rita Laura. Uma vocação de minoria: a expansão dos cultos afro-brasileiros na Argentina como processo de re-etnicização. Dados, Rio de Janeiro, v. 34, n. 2, p. 248-277, 1991.

SILVA, Vagner Gonçalves da (org.). Intolerância religiosa: impactos do neopentecostalismo no campo religioso afro-brasileiro. São Paulo: Edusp, 2007.

SILVA JUNIOR, Hédio. Notas sobre o sistema jurídico e intolerância. In: SILVA, Vagner Gonçalves da (org.). Intolerância religiosa: impactos do neopentecostalismo no campo-religioso brasileiro. São Paulo: Edusp, 2007. p. 303-331.

SOARES, Luiz Eduardo. Dimensões democráticas do conflito religioso no Brasil: a guerra dos pentecostais contra o afro-brasileiro. In: SOARES, Luiz Eduardo. Os dois corpos do presidente e outros ensaios. Rio de Janeiro: Relume Dumará/ISER, 1993. p. 203-216.

SOARES, Mariza de Carvalho. Guerra Santa no país do sincretismo. Cadernos do ISER, Dossiê Sinais dos Tempos: diversidade religiosa no Brasil, n. 23, p. 75-104, 1990.

SUPIOT, Alain. Homo juridicus: essais sur la fonction anthropologique du droit. Paris: Seuil, 2005. 


\section{Como CITAR ESTE ARTIGo:}

NICÁCIO, Camila Silva. Intolerância religiosa no estado de Minas Gerais: considerações a partir de uma pesquisa com boletins de ocorrência. Revista Direito GV, v. 17, n. 1, jan./abr. 2021, e2106. https://doi.org/10.1590/ 2317-6172202106

\section{Camila Silva Nicácio}

Doutora em Direito PELA Université PARIS I, PANTHÉon Sorbonne. Professora da Faculdade de Direito da Universidade Federal de Minas Gerais (UFMG).

cnicaciolufmg.br 